\title{
Searching the Correct and Appropriate Deterrence Function General Formula for Calculating Gravity Trip Distribution Model
}

\author{
Hitapriya Suprayitno ${ }^{1}$
}

\begin{abstract}
Trip Distribution Model is a very important part of Transport Modeling. This is a result of a mathematical operation among Trip Generation, Generalized Cost Matrix, and Deterrence Function. Thus, it can be understood easily that having a correct and appropriate Deterrence Function Formula is important. Here, correct means that the curve form is in concordance with typical Trip Length Distribution pattern. While, appropriate means that the function is easy to be manipulated in getting a good conformity with the Trip Length Distribution. Three Deterrence Function types, i.e. negative power, negative exponential, and Tanner, were investigated. The investigation was done upon Negative Power Function, Negative Exponential Function and 4 combinations of Tanner Function. The research result indicates that the Negative Power and the Negative Exponential are correct. While, among the four Tanner Function combinations, the correct ones are only the Tanner Function - Negative Power Negative Exponential and the Tanner Function - Positive Power Negative Exponential. The correct and appropriate Deterrence Functions are the above four Basic Functions multiply by a Constant.
\end{abstract}

Keywords_Deterrence Function Formula, Behavior, Trip Distribution, Gravity Model, Transport Modeling.

\section{INTRODUCTION}

$\mathrm{T}$ ransport modeling can be classified into three types, i.e. the direct model, the conventional model and the unconventional model. For all of these three types, the Trip Distribution Modeling step is the most important one. Future Demand Prediction is calculated based on the Base Year Origin-Destination Matrix (OD Matrix). Therefore, having accurate enough Base Year OD Matrix is capital [1]-[8].

In Conventional Transport Model, the OD Matrix itself is a mathematical operation product of Trip Generation Value with Deterrence Value Matrix. While the Deterrence Value Matrix is a mathematical operation product of Generalized Cost Matrix with the Deterrence Function. It can be understood easily that having accurate Deterrence Function is capital. The Deterrence Function itself is a model of Trip Length Distribution (TLD) Pattern. The method to develop the deterrence function has been written, but the method seems a bit complicated and not straightforward. The writing of deterrence function, in certain academic texts, seems contains something incomplete and therefore could be misleading [1], [2], [8][12]. Thus, searching the correct and appropriate Deterrence Function needs to be done. This need is related to the conformity to general trip length distribution pattern and to the easiness to develop a Deterrence Function. In other words, the Deterrence Function must be correct and appropriate.

The TLD Pattern must be constructed based on a certain Trip Length Interval (TLI) value. It has been shown that the TLD Pattern varies a lot depends on the TLI value taken. A small research, which needs to be more developed, shows that a TLI value of $1-2 \mathrm{~km}$ length cannot be used. TLI value of $3 \mathrm{~km}$, started to give significant pattern form [13].

\footnotetext{
${ }^{1}$ Hitapriya Suprayitno Department of Civil Engineering, Institu Teknologi Sepuluh Nopember (ITS), Surabaya, 60111, Indonesia. Email: suprayitno.hita@gmail.com.
}

Thus, it is time to search for correct and appropriate Deterrence Functions Formula, to be used for calculating Trip Distribution.

The British Term Deterrence Function, in the United States, is called as Friction Factor. These two schools used the different formula to express the same thing. In British style, the Deterrence Functions are expressed in three different functions: the negative power function, the negative exponential function, and the Tanner function, which is a multiplication of a negative power and a negative exponential function. While, in United States style, the Friction Factor is generally modeled by statistical probability density function such as Poisson, Chi-Square, Weibull, Log-Pearson Type III, and Gamma function [1], [2], [10], [14].

This paper discusses the result of an attempt to search the correct and appropriate Deterrence Function. In Indonesia, the English style is more popular and widely used than the United States style. This attempt is based on British style function.

\section{METHOD}

This research was conducted by following these steps: statement of the background, defining the objective, executing literature review, reviewing the deterrence function behavior, choosing the correct and the most appropriate one, and finlized by conclusions. For this case, correct means that the function curve is in concordance with the natural various typical TLD Pattern. While appropriate means that the function can be easily manipulated to be able to represent the TLD Pattern well, or with a minimum error.

\section{LITERATURE REVIEW}

The trip distribution gravity model is a multiplication of trip generation value with the deterrence value matrix. 


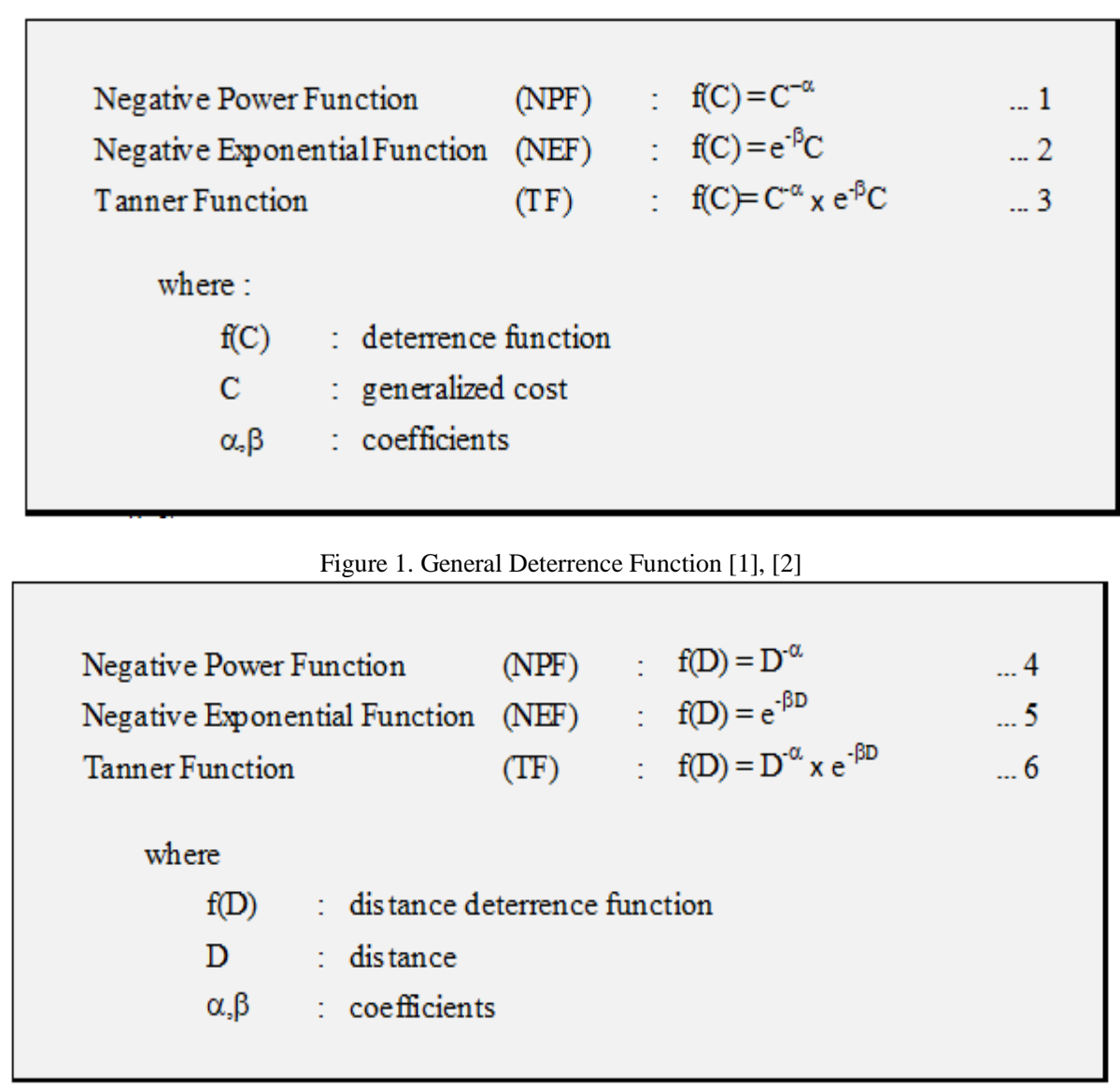

Fugure 2. Distance Deterrence Function - Basic Formula

While the deterrence value matrix is a mathaematical operation result of generalized cost matrixx with the deterrence function. The deterrence function itself is a representation or a model of the trip length distribution pattern. In general, there are three British style types of deterrence functions which are widely used [1], [2]. These are presented in Figure 1.

According to the research in developed countries, Trip Length Distribution Pattern has a specific form, which typically varies like Gamma Distribution form. The Gamma distribution as a representation of typical TLD Pattern variation is presented in Figure 3 [1], [2], [14][16].

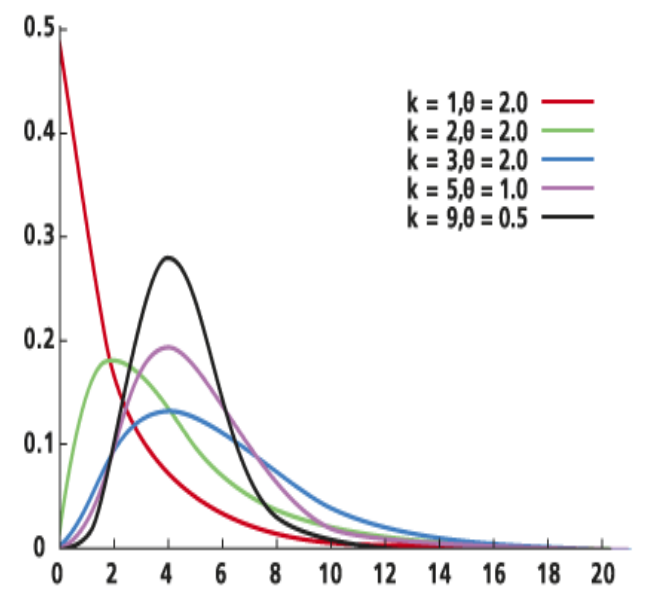

Figure 3. Gamma Distribution as Representation of Typical Trip Length Distribution Pattern

\section{SeArChing The Correct AND Appropriate DETERRENCE FUNCTION}

To ease the search of the Correct and Appropriate Deterrence Function, three groups of deterrence functions will be evaluated: the basic formula, the basic formula added by a constant, and the basic formula multiplied by a constant. For each group, the behavior of the three Deterrence Functions, i.e. the negative power, the negative exponential and the Tanner were each identified. In this identification, distance is used to represent a generalized cost. For such case, the deterrence function often called as distance deterrence function. The search process are presented below.

\section{A. Basic Formula}

On this first identification stage, a variation of coefficient values ( $\alpha$ and/or $\beta$ ) from 0.0 to 1.2 and Trip Length from 0.0 to 10.0 are investigated. The three behavior identifications are presented below. As distance deterrence function, the Basic Formula can be written as in Figure 2.

1) Negative Power Function

The calculation result indicated that for all of the $\alpha$ value, the Negative Power graph is always decreasing in a concave curving line. The graph is a horizontal straight line for $\alpha=0.0$, where $f(D)=1$. The general value of $f(D)$ is $0 \leq f(D) \leq 1$. The bigger the $\alpha$ value, the slope is steeper. The curve form is in concordance with Typical TLD Pattern. The starting pont is always at point $(1,1)$. This Deterrence Function can be considered as correct. The calculation table and the graph are presented in Table1 and Figure 4 
TABLE 1.

NEgATIVE POWER MODEL

\begin{tabular}{ccccc}
\hline \hline \multirow{2}{*}{ Length } & \multicolumn{4}{c}{$\boldsymbol{\alpha}$} \\
\cline { 2 - 5 } & $\mathbf{0 . 0}$ & $\mathbf{0 . 4}$ & $\mathbf{0 . 8}$ & $\mathbf{1 . 2}$ \\
\hline 0 & NC & NC & NC & NC \\
1 & 1.000 & 1.000 & 1.000 & 1.000 \\
2 & 1.000 & 0.758 & 0.574 & 0.435 \\
3 & 1.000 & 0.644 & 0.415 & 0.268 \\
4 & 1.000 & 0.574 & 0.330 & 0.189 \\
5 & 1.000 & 0.525 & 0.276 & 0.145 \\
6 & 1.000 & 0.488 & 0.238 & 0.116 \\
7 & 1.000 & 0.459 & 0.211 & 0.097 \\
8 & 1.000 & 0.435 & 0.189 & 0.082 \\
9 & 1.000 & 0.415 & 0.172 & 0.072 \\
10 & 1.000 & 0.398 & 0.158 & 0.063 \\
\hline \hline
\end{tabular}

Negative Power : D-a - $\mathrm{a}=0.0-1.2$

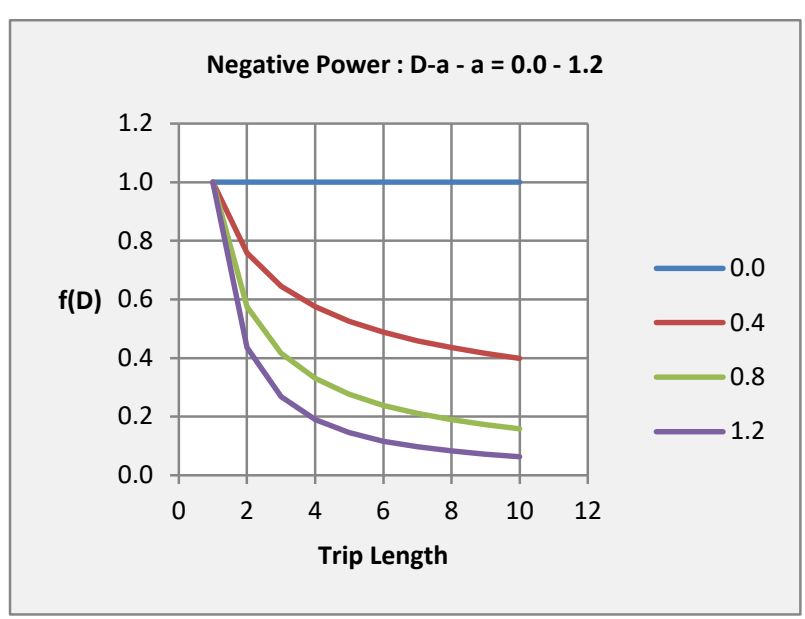

Figure 4. Negative Power Model.
TABEL 2.

NEGATIVE EXPONENTIAL

\begin{tabular}{lcccc}
\hline \hline \multirow{2}{*}{ Length } & \multicolumn{4}{c}{$\boldsymbol{\beta}$} \\
\cline { 2 - 5 } & $\mathbf{0 . 0}$ & $\mathbf{0 . 4}$ & $\mathbf{0 . 8}$ & $\mathbf{1 . 2}$ \\
\hline 0 & 1.000 & 1.000 & 1.000 & 1.000 \\
1 & 1.000 & 0.670 & 0.449 & 0.301 \\
2 & 1.000 & 0.449 & 0.202 & 0.091 \\
3 & 1.000 & 0.301 & 0.091 & 0.027 \\
4 & 1.000 & 0.202 & 0.041 & 0.008 \\
5 & 1.000 & 0.135 & 0.018 & 0.002 \\
6 & 1.000 & 0.091 & 0.008 & 0.001 \\
7 & 1.000 & 0.061 & 0.004 & 0.000 \\
8 & 1.000 & 0.041 & 0.002 & 0.000 \\
9 & 1.000 & 0.027 & 0.001 & 0.000 \\
10 & 1.000 & 0.018 & 0.000 & 0.000 \\
\hline \hline
\end{tabular}

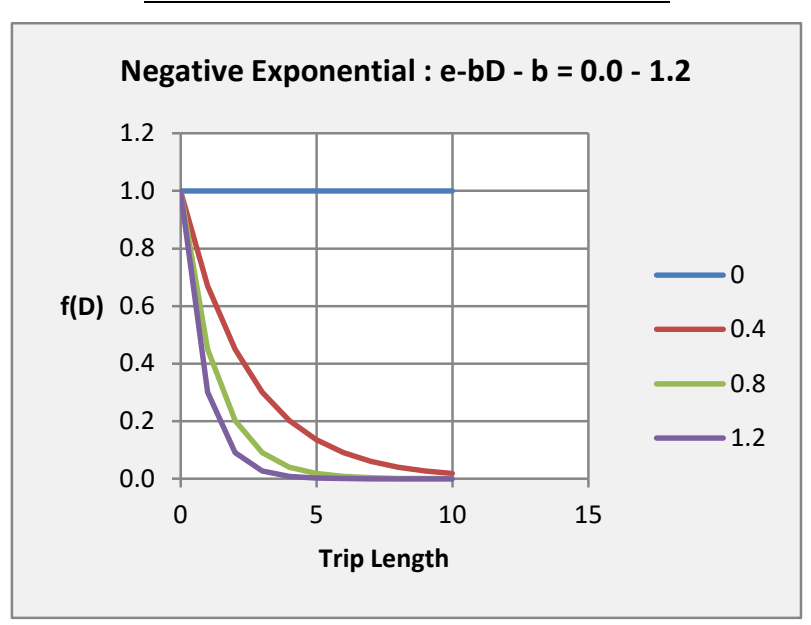

Figure 5. Negative Exponential

Tanner Function - Neg ative Power Negative Exponential

$$
\begin{aligned}
& \text { (TF-NN) : } f(D)=D^{-\alpha} \times \mathrm{e}^{-\beta D} \\
& \text { (TF-PP) }: f(D)=D^{\alpha} \times \mathrm{e}^{\beta D} \\
& \text { (TF-NP) }: f(D)=D^{-\alpha} \times \mathrm{e}^{\beta D} \quad \ldots 9 \\
& \text { (TF-PN) : } f(D)=D^{\alpha} \times \mathrm{e}^{-\beta D} \quad \ldots 10
\end{aligned}
$$$$
\text { Tanner Function - Positive Power Positive Exponential }
$$$$
\text { Tanner Function - Neg ative Power Positive Expon ential }
$$$$
\text { Tanner Function - Positive Power Negative Expon ential }
$$

where

$$
\begin{array}{ll}
\mathrm{f}(\mathrm{D}) & : \text { distance deterrence function } \\
\mathrm{D} & : \text { distance } \\
\alpha \beta & : \text { coefficients }
\end{array}
$$

\section{2) Negative Exponential Function}

Figure 6. Detterence Function - Tanner Formula Variations.

The calculation result indicated that for all of the $\beta$ value, the Negative Exponential graph has a decreasing concave curve, started from a point with coordinate value of $(0,1)$. The value $f(D)$ vary with $0>f(D) \geq 1$. The graph is a horizontal straight line for $\beta=0.0$. The bigger the $\beta$ value, the steeper is the slope. The Negative Exponential Function is conform to the Typical TLD Pattern. This Deterrence Function can be considered as correct. It must be noted that, in general, for the same coefficient value the Negative Exponential curve is steeper than the Negative Power curve. The starting pont is always at point $(0,1)$.
The calculation table and the graph are presented in Table 2 and Figure 5.

3) Tanner Function

The Tanner deterrence function, in principle, is a multiplication of Power Function and Exponential Function. In Transport Modeling literature, the Tanner function is normally written as a multiplication of Negative Power and Negative Exponential. But, here four combinations of Tanner Deterrence Function were investigated as written in Figure 6. 
Tanner Negative Power Negative Exponential (TF-NN) A Negative Power Negative Exponential Tanner Model for $\alpha=0.2$ and 4 differentt $\beta$ values of $0.0<\beta<1.2$ were investigated. This Tanner Function (TF-NN) graph is a concave decreasing line. All the curves are pretty much similar to the Negative Power function. It can be concluded that this Tanner Formula (TF-NN) is in concordance with the TLD Pattern. The calculation and the graph are presented in Table 3 and Figure 6.

TABLE 3.

TANNER - Negative Power Negative ExPONENTIAL

\begin{tabular}{ccccc}
\hline \hline \multirow{2}{*}{ Length } & \multicolumn{4}{c}{ b } \\
\cline { 2 - 5 } & $\mathbf{0 . 0}$ & $\mathbf{0 . 4}$ & $\mathbf{0 . 8}$ & $\mathbf{1 . 2}$ \\
\hline 0 & NC & NC & NC & NC \\
1 & 1.000 & 1.000 & 1.000 & 1.000 \\
2 & 0.871 & 0.871 & 0.871 & 0.871 \\
3 & 0.803 & 0.803 & 0.803 & 0.803 \\
4 & 0.758 & 0.758 & 0.758 & 0.758 \\
5 & 0.725 & 0.725 & 0.725 & 0.725 \\
6 & 0.699 & 0.699 & 0.699 & 0.699 \\
7 & 0.678 & 0.678 & 0.678 & 0.678 \\
8 & 0.660 & 0.660 & 0.660 & 0.660 \\
9 & 0.644 & 0.644 & 0.644 & 0.644 \\
10 & 0.631 & 0.631 & 0.631 & 0.631 \\
\hline \hline
\end{tabular}

TABLE 4.

TANNER - Positive POWER Positive EXPONENTIAL

\begin{tabular}{ccccc}
\hline \hline \multirow{2}{*}{ Length } & \multicolumn{3}{c}{$\boldsymbol{\beta}$} \\
\cline { 2 - 5 } & $\mathbf{0 . 0}$ & $\mathbf{0 . 4}$ & $\mathbf{0 . 8}$ & $\mathbf{1 . 2}$ \\
\hline 0 & 0.0 & 0.0 & 0.0 & 0.0 \\
1 & 1.0 & 1.5 & 2.2 & 3.3 \\
2 & 1.1 & 2.6 & 5.7 & 12.7 \\
3 & 1.2 & 4.1 & 13.7 & 45.6 \\
4 & 1.3 & 6.5 & 32.4 & 160.3 \\
5 & 1.4 & 10.2 & 75.3 & 556.6 \\
6 & 1.4 & 15.8 & 173.9 & $1,916.7$ \\
7 & 1.5 & 24.3 & 399.1 & $6,562.9$ \\
8 & 1.5 & 37.2 & 912.2 & $22,379.2$ \\
9 & 1.6 & 56.8 & $2,078.6$ & $76,072.7$ \\
10 & 1.6 & 86.5 & $4,724.5$ & $257,949.0$ \\
\hline \hline
\end{tabular}

TABLE 5.

TANNER - Negative PoWER Positive EXPONENTIAL

\begin{tabular}{ccccc}
\hline \hline \multirow{2}{*}{ Length } & \multicolumn{4}{c}{$\boldsymbol{\beta}$} \\
\cline { 2 - 5 } & $\mathbf{0 . 0}$ & $\mathbf{0 . 4}$ & $\mathbf{0 . 8}$ & $\mathbf{1 . 2}$ \\
\hline 0 & NC & NC & NC & NC \\
1 & 1.0 & 1.5 & 2.2 & 3.3 \\
2 & 0.9 & 1.9 & 4.3 & 9.6 \\
3 & 0.8 & 2.7 & 8.8 & 29.4 \\
4 & 0.8 & 3.8 & 18.6 & 92.1 \\
5 & 0.7 & 5.4 & 39.6 & 292.4 \\
6 & 0.7 & 7.7 & 84.9 & 936.0 \\
7 & 0.7 & 11.1 & 183.2 & $3,013.4$ \\
8 & 0.7 & 16.2 & 397.1 & $9,741.1$ \\
9 & 0.6 & 23.6 & 863.1 & $31,588.7$ \\
10 & 0.6 & 34.4 & $1,880.9$ & $102,691.3$ \\
\hline \hline
\end{tabular}

Tanner Positive Power Positive Exponential (TF-PP) Positive Power Positive Exponential Tanner Model for $\alpha=$ 0.2 and 4 differentt $\beta$ values of $0.0<\beta<1.2$ were investigated. The calculation result indicates that the $f(D)$ value increase as the trip length increase, in a concave curve line. This is not in concordance with normal trip length distribution pattern. It can be concluded that the formula is not correct. This formula cannot be used. The calculation and the graph are presented in Table 4 and Figure 7.

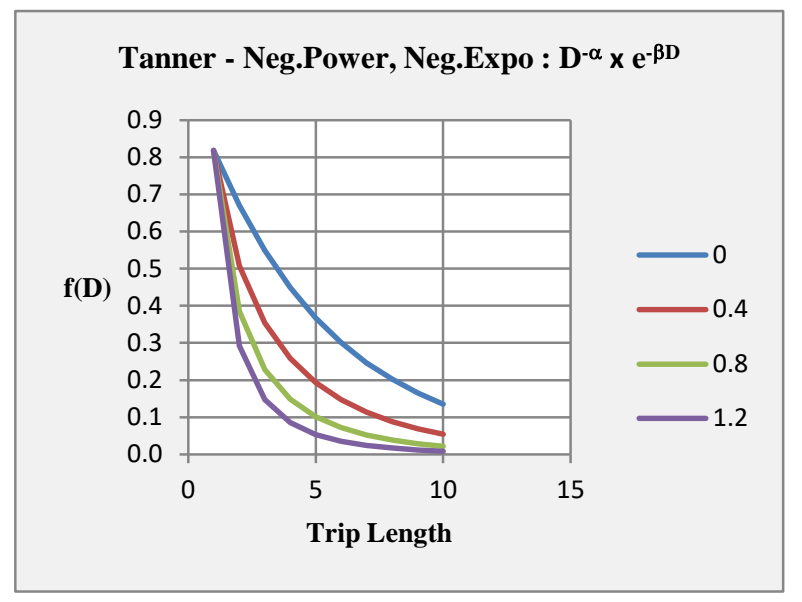

Figure 6. Tanner - Negative Power Negative Exponential

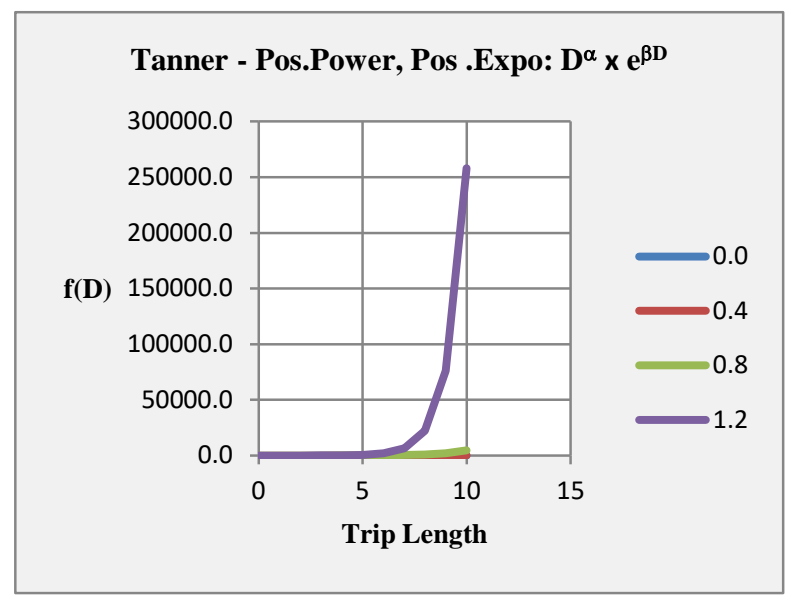

Figure 7. Tanner - Positive Power Positive Exponential

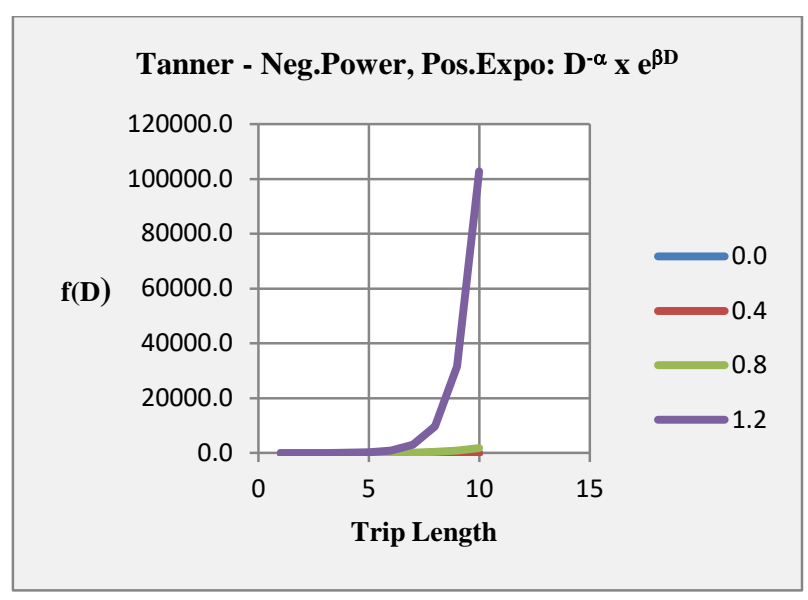

Figure 8. Negative Power Positive Exponential 
Tanner Negative Power Positive Exponential (TF-NP) A Negative Power Positive Exponential Tanner Model was investigated for the same value of $\alpha, \beta$ and trip length. All the curve forms are pretty much similar to Tanner Negative Power Positive Exponential function, except that the curve is less steep. This Tanner function cannot be used since this is not in concordance with the Typical TLD Pattern. The calculation and the graph are presented in Table 5 and Figure 8.

\section{Tanner Positive Power Negative Exponential (TF-PN)}

The investigation on Tanner Function Positive Power Negative Exponential was done in two steps: with varying the $\alpha$ value and with varying the $\beta$ value.

TF-PN with varying the $\alpha$ value.

For this case, the $\beta$ value is set $\beta=0.4$, while the $\alpha$ value is set in various $\alpha=0.0-1.2$. The calculation gives the following curve pattern. In general, the curve is started from a low certain value at low trip length, and then the curve increasing very steeply in a convex form, until it reaches a peak point at a short distance, the curve then decreasing gradually in a concave form. The peak is located at absis $=\alpha / \beta$. These Tanner graphs are in concordance with the TLD Pattern. So this Tanner function is correct and the one which is different from the Negative Power

TABLE 6.

TANNER - Positive POWER NEGATIVE EXPONENTIAL

\begin{tabular}{ccccc}
\hline \hline \multirow{2}{*}{ Length } & \multicolumn{4}{c}{$\boldsymbol{\alpha}$} \\
\cline { 2 - 5 } & $\mathbf{0 . 0}$ & $\mathbf{0 . 4}$ & $\mathbf{0 . 8}$ & $\mathbf{1 . 2}$ \\
\hline 0 & 0.000 & 0.000 & 0.000 & 0.000 \\
1 & 0.670 & 0.670 & 0.670 & 0.670 \\
2 & 0.449 & 0.593 & 0.782 & 1.032 \\
3 & 0.301 & 0.467 & 0.725 & 1.126 \\
4 & 0.202 & 0.352 & 0.612 & 1.066 \\
5 & 0.135 & 0.258 & 0.490 & 0.934 \\
6 & 0.091 & 0.186 & 0.380 & 0.779 \\
7 & 0.061 & 0.132 & 0.288 & 0.628 \\
8 & 0.041 & 0.094 & 0.215 & 0.494 \\
9 & 0.027 & 0.066 & 0.158 & 0.382 \\
10 & 0.018 & 0.046 & 0.116 & 0.290 \\
\hline \hline
\end{tabular}

TABLE 7.

TANNER - POSITIVE POWER NEGATIVE EXPONENTIAL

\begin{tabular}{ccccc}
\hline \hline \multirow{2}{*}{ Length } & \multicolumn{4}{c}{$\boldsymbol{\beta}$} \\
\cline { 2 - 5 } & $\mathbf{0 . 0}$ & $\mathbf{0 . 4}$ & $\mathbf{0 . 8}$ & $\mathbf{1 . 2}$ \\
\hline 0 & 0.000 & 0.000 & 0.000 & 0.000 \\
1 & 1.000 & 0.670 & 0.449 & 0.301 \\
2 & 1.320 & 0.593 & 0.266 & 0.120 \\
3 & 1.552 & 0.467 & 0.141 & 0.042 \\
4 & 1.741 & 0.352 & 0.071 & 0.014 \\
5 & 1.904 & 0.258 & 0.035 & 0.005 \\
6 & 2.048 & 0.186 & 0.017 & 0.002 \\
7 & 2.178 & 0.132 & 0.008 & 0.000 \\
8 & 2.297 & 0.094 & 0.004 & 0.000 \\
9 & 2.408 & 0.066 & 0.002 & 0.000 \\
10 & 2.512 & 0.046 & 0.001 & 0.000 \\
\hline \hline
\end{tabular}

Function and Negative Exponential Function. The calculation data and the graph are presented in Table 6 and Figure 9.

TF-PN with varying the $\beta$ value

Another combination value of $\alpha$ and $\beta$ is investigated. The $\alpha$ value is set at 0.4 and the $\beta$ value varies $\beta=0.0-$ 1.2. It gave the very similar pattern, started from a low value at low trip length, follow by a convex increasing curve until it reaches the peak point, and then the curve decreasing less steep in a concave curve. The graph form is also in concordance with the TLD Pattern. The Calculation Data and Graph are presented in Table 7 and Figure 10.

\section{Summary of Tanner Function}

Among the four variations investigated, the Tanner Negative Power Negative Exponential (TF-NN) give similar TLD Pattern as the Negative Power Function and the Negative Exponential Function; while the Tanner Positive Power Negative Exponential give the other classical form of an increasing-decreasing curve. These two Tanner Functions are correct because they are in concordance with the typical natural form of TLD Pattern. The other two Tanner Models give wrong TLD Pattern, with always higher value for higher trip length. A summary of 4 Tanner Functions is presented in Table 8.

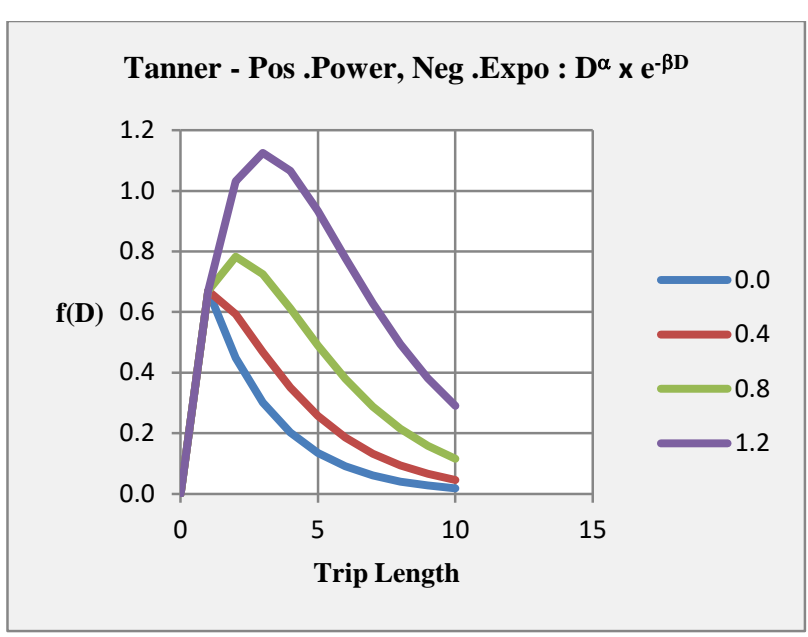

Figure 9. Tanner - Positive Power Negative Exponential

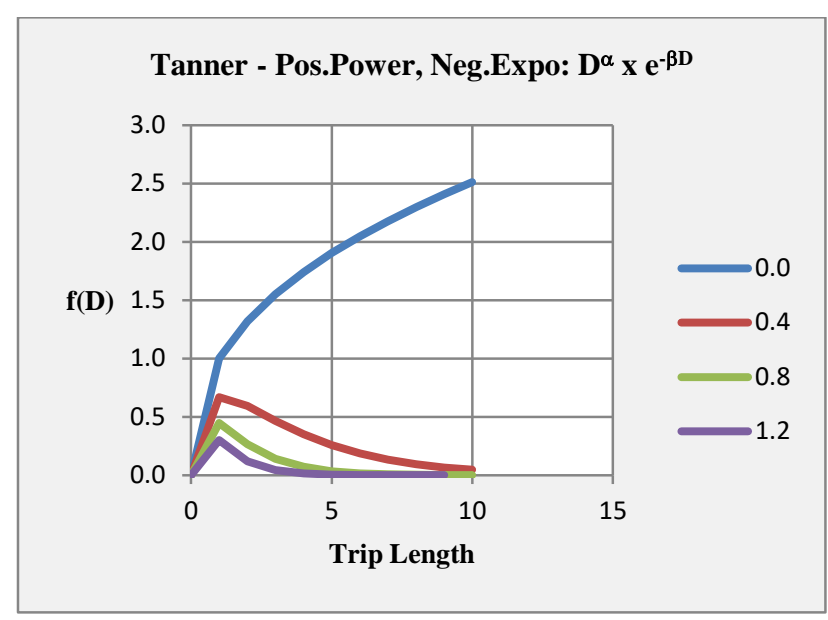

Figure 10. Tanner - Positive Power Negative Exponential 
TABEL 8.

SUMMARY A AND B SIGN VARIATION FOR TANNER MODEL

\begin{tabular}{ccccc}
\hline \hline No & $\boldsymbol{\alpha}$ & $\boldsymbol{\beta}$ & Form & Correctness \\
\hline 1 & - & - & always decreasing & YES, but similar to NPF \& NEF \\
2 & + & - & increasing-decreasing & YES \\
3 & - & + & always increasing & No \\
4 & + & + & always increasing & No \\
\hline \hline
\end{tabular}

\begin{tabular}{|c|c|c|c|c|}
\hline \multicolumn{2}{|c|}{ Negative Power Function } & (NPF) & $: \quad f(D)=D^{-\alpha}$ & ... 11 \\
\hline \multicolumn{2}{|c|}{ Negative Exponential Function } & (NEF) & $: f(D)=e^{\beta D}$ & $\ldots 12$ \\
\hline \multicolumn{2}{|c|}{ T anner Function - Negative Power Negative Exponential } & $(\mathrm{TF}-\mathrm{NN})$ & $: f(D)=D^{-\alpha} \times e^{-\beta D}$ & $\ldots 13$ \\
\hline \multicolumn{2}{|c|}{ T anner Function - Positive Power Negative Exponential } & $(\mathrm{TF}-\mathrm{PN})$ & $: f(D)=D^{\alpha} \times e^{-\beta D}$ & ... 14 \\
\hline \multicolumn{5}{|l|}{ where } \\
\hline$f(D)$ & \multicolumn{4}{|l|}{ : distance deterrence function } \\
\hline $\mathrm{D}$ & \multicolumn{4}{|l|}{ : distance } \\
\hline$\alpha, \beta$ & \multicolumn{4}{|l|}{ : coefficients } \\
\hline
\end{tabular}

Figure 11. Distance Deterrence Function - Correct Basic Formula

TABEL 9.

NEGATIVE POWER FUNCTION $+\mathrm{C}_{0}$

\begin{tabular}{ccccc}
\hline \hline \multirow{2}{*}{ Dist } & \multicolumn{4}{c}{ C } \\
\cline { 2 - 5 } & 0 & 1 & 2 & 3 \\
\hline 0 & NC & NC & NC & NC \\
1 & 1.000 & 2.000 & 3.000 & 4.000 \\
2 & 0.758 & 1.758 & 2.758 & 3.758 \\
3 & 0.644 & 1.644 & 2.644 & 3.644 \\
4 & 0.574 & 1.574 & 2.574 & 3.574 \\
5 & 0.525 & 1.525 & 2.525 & 3.525 \\
6 & 0.488 & 1.488 & 2.488 & 3.488 \\
7 & 0.459 & 1.459 & 2.459 & 3.459 \\
8 & 0.435 & 1.435 & 2.435 & 3.435 \\
9 & 0.415 & 1.415 & 2.415 & 3.415 \\
10 & 0.398 & 1.398 & 2.398 & 3.398 \\
\hline \hline
\end{tabular}

\section{Summary of Basic Formula}

The Basic Model Formula investigation, for the three Deterrence Functions, has indicated that the Negative Power Function and the Negative Exponential Function are logical enough, and therefore they are correct. On the other hand, among the four combinations of Tanner Functions, there are only two combinations which are correct. The four correct Distance Deterrence Functions, the Basic Formula, are written in Figure 11.

\section{B. Basic Formula Added by Constant}

The second group of investigation is to investigate the effect of Basic Formula Added by a Constant. The general formula is as follow:

where:

$$
\mathrm{f}(\mathrm{D})_{\mathrm{AC}}=\mathrm{c}_{0}+\mathrm{f}(\mathrm{D})_{\mathrm{BF}}
$$

$$
\begin{array}{ll}
\mathrm{f}(\mathrm{D})_{\mathrm{AC}} & : \mathrm{f}(\mathrm{D}) \text { added by } \mathrm{C}_{0} \\
\mathrm{f}(\mathrm{D})_{\mathrm{BF}} & : \mathrm{f}(\mathrm{D}) \text {, the basic formula } \\
\mathrm{C}_{0} & : \text { constant. }
\end{array}
$$

It has been shown above that the Tanner Function Negative Power Negative Exponential is very similar in curve form as the curve form of Negative Power Function and of Negative Exponential Function, therefore the investigation was done only for three Basic Formula: NPF,

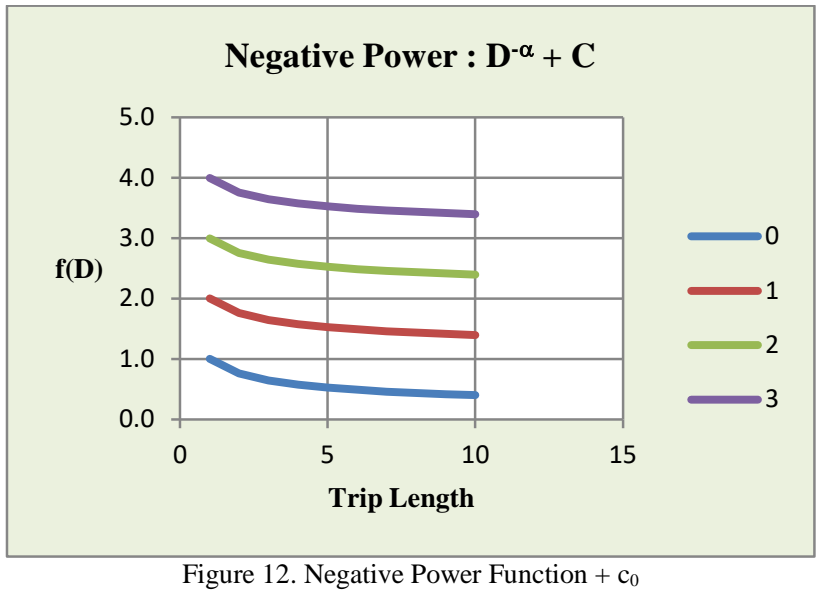

NEF, and TF-PN. Four value of $\mathrm{c}_{0}$ were used, i.e. $\mathrm{c}_{0}=0-$ 3. The experiments for the three cases are presented as follow.

1) Negative Power Function $+c_{0}$

The addition of a constant to Negative Power Function does not change the curve form. The addition gives the effect of shifting the curve upward and downward, depends on the $\mathrm{c}_{0}$ value. The calculation and the graph are presented Table 9 and Figure 12.

2) Negative Exponential Function $+c_{0}$

Same as above, the addition of a constant to Negative Exponential does not change the curve form. The addition gives the effect of shifting the curve upward and downward, depends on the $\mathrm{c}_{0}$ value. The calculation and the graph are presented Table 10 and Figure 13.

3) Tanner Function $+c_{0}$

Again, the addition of a constant to Tanner Function does not change the curve form. The addition gives the effect of shifting the curve upward and downward, depends on the $\mathrm{c}_{0}$ value. The calculation and the graph are presented Table 11 and Figure 14. 
TABEL 10.

NEGATIVE EXPONENTIAL $+\mathrm{C}_{0}$

\begin{tabular}{ccccc}
\hline \hline \multirow{2}{*}{ Dist. } & \multicolumn{4}{c}{ C } \\
\cline { 2 - 5 } & 0 & 1 & 2 & 3 \\
\hline 0 & 1.000 & 2.000 & 3.000 & 4.000 \\
1 & 0.670 & 1.670 & 2.670 & 3.670 \\
2 & 0.449 & 1.449 & 2.449 & 3.449 \\
3 & 0.301 & 1.301 & 2.301 & 3.301 \\
4 & 0.202 & 1.202 & 2.202 & 3.202 \\
5 & 0.135 & 1.135 & 2.135 & 3.135 \\
6 & 0.091 & 1.091 & 2.091 & 3.091 \\
7 & 0.061 & 1.061 & 2.061 & 3.061 \\
8 & 0.041 & 1.041 & 2.041 & 3.041 \\
9 & 0.027 & 1.027 & 2.027 & 3.027 \\
10 & 0.018 & 1.018 & 2.018 & 3.018 \\
\hline \hline
\end{tabular}

TABLE 11.

TANNER DETERRENCE FUNCTION $+\mathrm{C}_{0}$

\begin{tabular}{ccccc}
\hline \hline \multirow{2}{*}{ Length } & \multicolumn{4}{c}{ C } \\
\cline { 2 - 5 } & $\mathbf{0}$ & $\mathbf{1}$ & $\mathbf{2}$ & $\mathbf{3}$ \\
\hline 0 & 0.000 & 1.000 & 2.000 & 3.000 \\
1 & 0.819 & 1.819 & 2.819 & 3.819 \\
2 & 0.884 & 1.884 & 2.884 & 3.884 \\
3 & 0.852 & 1.852 & 2.852 & 3.852 \\
4 & 0.782 & 1.782 & 2.782 & 3.782 \\
5 & 0.700 & 1.700 & 2.700 & 3.700 \\
6 & 0.617 & 1.617 & 2.617 & 3.617 \\
7 & 0.537 & 1.537 & 2.537 & 3.537 \\
8 & 0.464 & 1.464 & 2.464 & 3.464 \\
9 & 0.398 & 1.398 & 2.398 & 3.398 \\
10 & 0.340 & 1.340 & 2.340 & 3.340 \\
\hline \hline
\end{tabular}

TABLE 12.

NEGATIVE POWER FUNCTION MULTIPLY BY C ${ }_{0}$

\begin{tabular}{lllll}
\hline \hline \multirow{2}{*}{ Dist } & \multicolumn{4}{c}{ C } \\
\cline { 2 - 5 } & \multicolumn{1}{c}{$\mathbf{0}$} & \multicolumn{1}{c}{$\mathbf{1}$} & \multicolumn{1}{c}{$\mathbf{2}$} & \multicolumn{1}{c}{$\mathbf{3}$} \\
\hline 0 & NC & NC & NC & NC \\
1 & 0.000 & 1.000 & 2.000 & 3.000 \\
2 & 0.000 & 0.871 & 1.741 & 2.612 \\
3 & 0.000 & 0.803 & 1.605 & 2.408 \\
4 & 0.000 & 0.758 & 1.516 & 2.274 \\
5 & 0.000 & 0.725 & 1.450 & 2.174 \\
6 & 0.000 & 0.699 & 1.398 & 2.096 \\
7 & 0.000 & 0.678 & 1.355 & 2.033 \\
8 & 0.000 & 0.660 & 1.320 & 1.979 \\
9 & 0.000 & 0.644 & 1.289 & 1.933 \\
10 & 0.000 & 0.631 & 1.262 & 1.893 \\
\hline \hline
\end{tabular}

4) Summary of Basic Formula Added by a Constant

In general, the effect of $c_{0}$ addition is shifting the graph up-and-down, with still having the same basic curve form. The effect of adding a Constant must be furthermore evaluated by using real data. It may be possible that small value of $c_{0}$ might increase the accuracy of the Deterrence Function. In general, Basic Formula Added by a Constant could be considered as Inappropriate.

\section{Basic Formula Multiplied by Constant}

The third group of experiments is to investigate the effect of Basic Formula Multiplied by a Constant. The general formula is as follow:

$$
\mathrm{f}(\mathrm{D})_{\mathrm{MC}}=\mathrm{C}_{0} \times \mathrm{f}(\mathrm{D})_{\mathrm{BF}}
$$

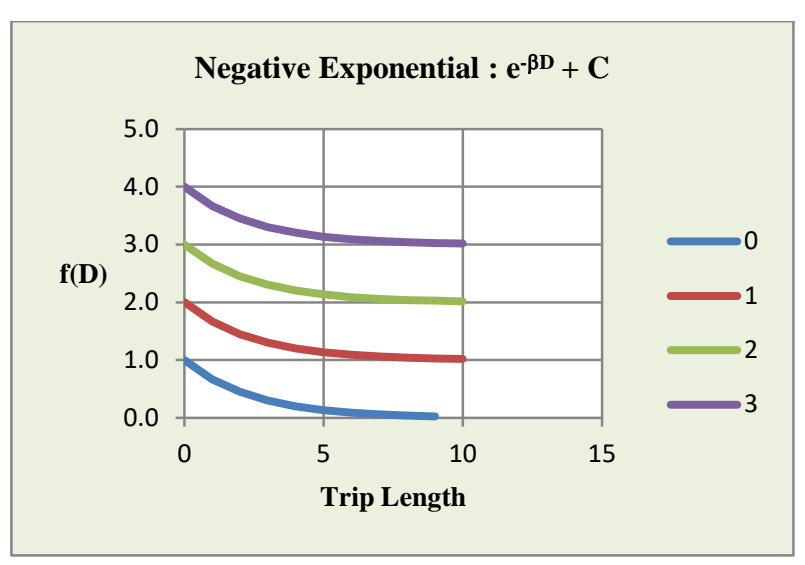

Figure 13. Negative Exponential $+\mathrm{c}_{0}$

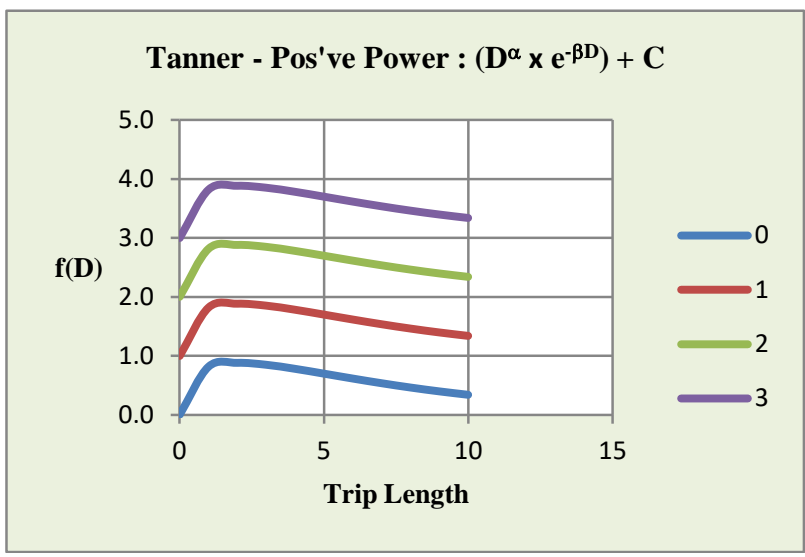

Figure 14. Tanner Deterrence Function $+\mathrm{c}_{0}$

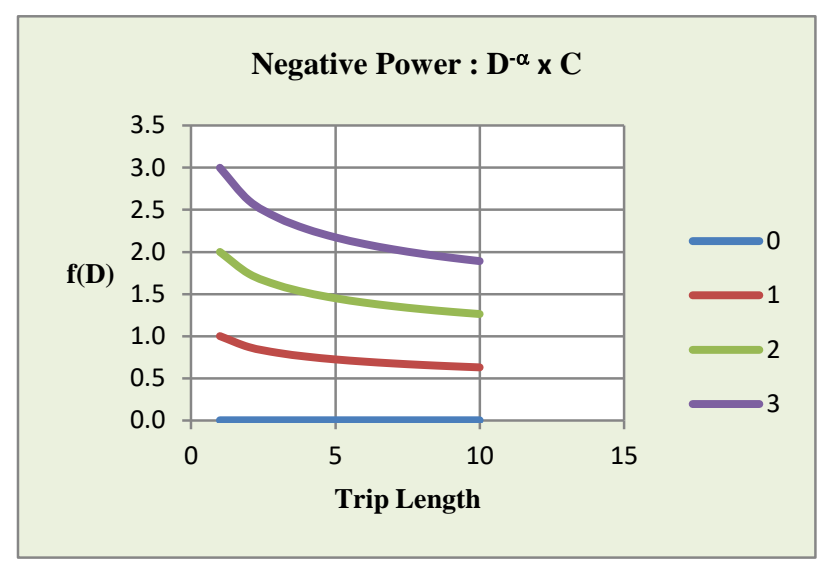

Figure 15. Negative Power Function multiply by $\mathrm{c}_{0}$

where:

$\mathrm{f}(\mathrm{D})_{\mathrm{MC}} \quad$ : $\mathrm{f}(\mathrm{D})$ multiplied by Co

$\mathrm{f}(\mathrm{D})_{\mathrm{BF}}$ : $\mathrm{f}(\mathrm{D})$, the basic formula

$\mathrm{C}_{0} \quad$ : constant.

Again, three type of Basic Formula Multiplied by Constant have been investigated, i.e. NPF, NEF, and TF$\mathrm{PN}$. Four values of $\mathrm{c}_{0}$ were used, i.e. 0 - 3. The experiment results for these three cases are presented as follow.

1) Negative Power Function $x c_{0}$

The multiplication of a constant with Negative Power Function gives the effect of steepening the slope. Depends on the $\mathrm{c}_{0}$ value, the higher the $\mathrm{c}_{0}$ value the steeper is the slope. The calculation and the graph are presented Table 12 and Figure 15. 
2) Negative Exponential Function $x C$

The same as above, the multiplication of a constant with Negative Exponential Function give the effect of steepening the slope. Depends on the $\mathrm{c}_{0}$ value, higher $\mathrm{c}_{0}$ value produce steeper slope. The calculation and the graph are presented Table 13 and Figure 16.

3) Tanner Function $x c_{0}$

Again, the multiplication of a constant with Tanner Function gives the effect of steepening the slope. Depends on the c0 value, the effect is the same as above. The calculation and the graph are presented Table 14 and Figure 17.

4) Summary of Basic Formula Multiplied by a Constant The multiplication of $\mathrm{c}_{0}$ to the Basic Formula has an effect to increase or decrease the slope steepness. This effect is very useful to face the different natural form of TLD Pattern. For example, there must be a case, for which the $\alpha$ and $\beta$ coefficients give already the maximum effect on presenting the steepness of the curve, but then the $\alpha$ and

TABEL 13.

NEGATIVE EXPONENTIAL FUNCTION MULTIPLY BY C 0

\begin{tabular}{ccccc}
\hline \hline \multirow{2}{*}{ Dist. } & \multicolumn{4}{c}{$\mathbf{C}$} \\
\cline { 2 - 5 } & $\mathbf{0}$ & $\mathbf{1}$ & $\mathbf{2}$ & $\mathbf{3}$ \\
\hline 0 & 0.000 & 1.000 & 2.000 & 3.000 \\
1 & 0.000 & 0.819 & 1.637 & 2.456 \\
2 & 0.000 & 0.670 & 1.341 & 2.011 \\
3 & 0.000 & 0.549 & 1.098 & 1.646 \\
4 & 0.000 & 0.449 & 0.899 & 1.348 \\
5 & 0.000 & 0.368 & 0.736 & 1.104 \\
6 & 0.000 & 0.301 & 0.602 & 0.904 \\
7 & 0.000 & 0.247 & 0.493 & 0.740 \\
8 & 0.000 & 0.202 & 0.404 & 0.606 \\
9 & 0.000 & 0.165 & 0.331 & 0.496 \\
10 & 0.000 & 0.135 & 0.271 & 0.406 \\
\hline \hline
\end{tabular}

TABEL 14.

TANNER FUNCTION MULTIPLY BY $\mathrm{C}_{0}$

\begin{tabular}{ccccc}
\hline \hline \multirow{2}{*}{ Dist } & \multicolumn{4}{c}{ C } \\
\cline { 2 - 5 } & $\mathbf{0}$ & $\mathbf{1}$ & $\mathbf{2}$ & $\mathbf{3}$ \\
\hline 0 & 0.000 & 0.000 & 0.000 & 0.000 \\
1 & 0.000 & 0.819 & 1.637 & 2.456 \\
2 & 0.000 & 1.016 & 2.032 & 3.048 \\
3 & 0.000 & 1.061 & 2.122 & 3.183 \\
4 & 0.000 & 1.032 & 2.065 & 3.097 \\
5 & 0.000 & 0.966 & 1.932 & 2.899 \\
6 & 0.000 & 0.883 & 1.765 & 2.648 \\
7 & 0.000 & 0.793 & 1.585 & 2.378 \\
8 & 0.000 & 0.703 & 1.406 & 2.109 \\
9 & 0.000 & 0.618 & 1.236 & 1.853 \\
10 & 0.000 & 0.539 & 1.078 & 1.616 \\
\hline \hline
\end{tabular}

$\beta$ value are not capable to attain the existing steepness. For cases like this, the $\mathrm{c}_{0}$ can play the role to increase the steepness of the curve. A special investigation on this case needs to be done. Therefore, Basic Formula multiplied by a Constant is very appropriate to face such problem. This type of formula must be used in developing a Deterrence Function.

\section{Overall Summary}

The experiment shows us that it is better to use the Basic Formula Multiplied by a Constant. This is to facilitate the data which are expressed in a number of trips. The data can be of a certain value and such steepness, that the Basic Formula needs to be multiplied by a constant to reach that nature. The $\mathrm{c}_{0}$ will not affect the total number of trips in the Origin-Destination Matrix since it will be compensated by the total number of Trip Production. The four correct and appropriate Distance Deterrence Functions are presented in Figure 18.

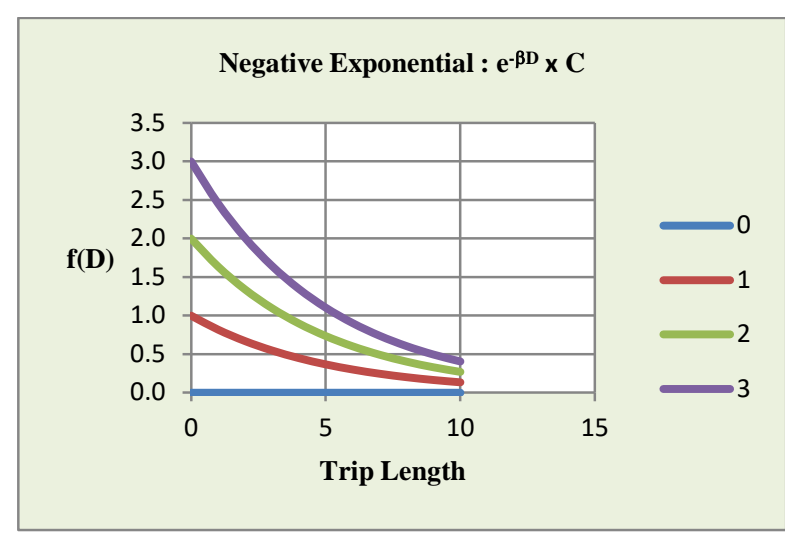

Figure 16. Negative Exponential Function multiply by $\mathrm{c}_{0}$

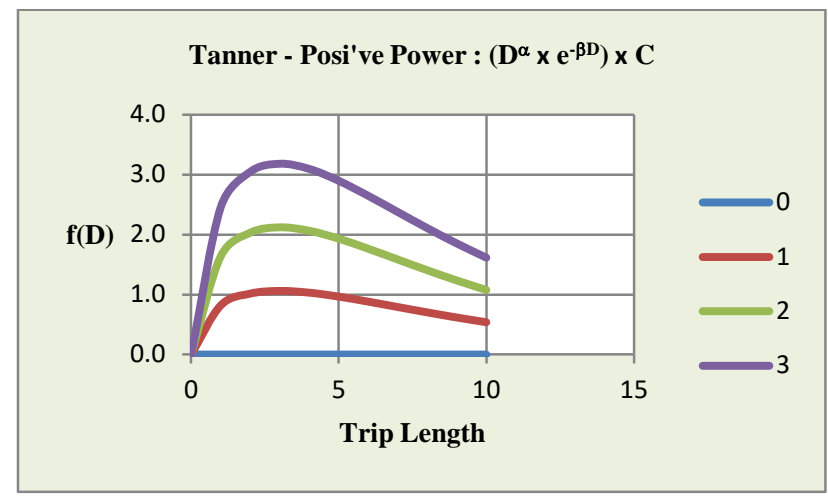

Figure 17. Tanner Function multiply by $\mathrm{c}_{0}$
Negative Power Function

Negative Exponential Function

Tanner Function - Neg ative Power Negative Exp onential

Tanner Function - Positive Power Negative Exponentia1

where

$f(D) \quad$ : distance deterrence function

$\mathrm{D}$

$\alpha, \beta$

$c_{0}$

constant 


\begin{tabular}{|c|c|c|c|c|}
\hline \multicolumn{2}{|c|}{ Negative Power Function } & $(\mathrm{NPF})$ & $: \quad \mathrm{f}(\mathrm{C})=\mathrm{c}_{0} \times \mathrm{C}^{-\alpha}$ & $\ldots 21$ \\
\hline \multicolumn{2}{|c|}{ Negative Expon en tial Function } & $(\mathrm{NEF})$ & $: f^{\prime}(C)=c_{0} \times e^{-\beta x}$ & $\ldots 22$ \\
\hline \multirow{2}{*}{\multicolumn{2}{|c|}{$\begin{array}{l}\text { Tanner Function - Negativ e Power Negative Exponential } \\
\text { Tanner Function - Positive Power Negativ e Exponential }\end{array}$}} & $(\mathrm{TF}-\mathrm{NN})$ & $: f(C)=c_{0} \times C^{-\alpha} \times e^{-\beta C}$ & $\ldots 23$ \\
\hline & & $(\mathrm{TF}-\mathrm{PN})$ & $: f^{\prime}(C)=c_{0} \times C^{\alpha \alpha} \times e^{-\beta C}$ & ... 24 \\
\hline \multicolumn{5}{|l|}{ where } \\
\hline $\mathrm{f}(\mathrm{C})$ & \multicolumn{4}{|l|}{ : deterrence function } \\
\hline $\mathrm{C}$ & \multicolumn{4}{|l|}{ : generalized cost } \\
\hline$\alpha, \beta$ & \multicolumn{4}{|l|}{ : coefficients } \\
\hline $\mathrm{c}_{0}$ & \multicolumn{4}{|l|}{ : constant } \\
\hline
\end{tabular}

Figure 19. Deterrence Function - Correct and Appropriate General Formula

The above Distance Deterrence Functions can be easily transformed into general Deterrence Functions, based on generalized cost, by changing the variable $\mathrm{D}$ (distance) with $C$ (generalized cost). The general four correct and appropriate Deterrence Functions are presented in Figure 19.

\section{CONCLUSIONS}

Research objective has been fulfilled. The correct and appropriate deterrence functions have been identified. Several important conclusions can be drawn as follow.

- Negative Power and Negative Exponential formula are all correct.

- Among the four Tanner formula combinations, the correct Tanner formula are only the Tanner Function Negative Power Negative Exponential (TF-NN) and the Tanner Function Positive Power Negative Exponential (TF-PN).

- Among the three types of Deterrence Function Formula, i.e. Basic, Basic Added by Constant and Basic Multiplied by Constant, the most appropriate to be used is the Basic Formula Multiplied by a Constant.

This research must be further developed toward the investigation of the general variety of TLD Pattern for Indonesian cases, the understanding of the TLD Behavior by investigating TLD Pattern for different type of cases, the development method of the Deterrence Function Model either British Style or American Style, the comparison of three Deterrence Function : Negative Power, Negative Exponential \& Tanner - Negative Power Negative Exponential, the identification of the effect of added a constant by using real data, and the behavior investigation of the function Tanner - Positive Power Negative Exponential and Tanner - Negative Power Negative Exponential.

Notes: This research is a part of main research on Trip Distribution Modeling for Direct Modeling, Conventional Modeling, and Unconventional Modeling.

\section{REFERENCES}

[1] O. Z. Tamin, Perencanaan,Pemodelan,\&amp; Rekayasa Transportasi :Teori, Contoh Soal, dan Aplikasi. Bandung: ITB, 2008.

[2] J. de D. Ortúzar and L. G. Willumsen, Modelling transport Chichester: John Wiley \& Sons Ltd, 2004.

[3] H. Suprayitno, "Metoda Pemodelan Kebutuhan Angkutan Barang Perkotaan - Kasus Kota Surabaya,” in Prosiding Simposium II FSTPT, 1999.

[4] H. Suprayitno, "Penyusunan Metoda Perhitungan Model Distribusi Perjalanan Berbasis Data Volume Lalu Lintas pada Kasus Pembebanan All-or-Nothing," in Seminar Nasional Aplikasi Teknik Prasarana Wilayah, 2015, p. D-181.

[5] H. Suprayitno and V. A. Upa, "Special Conventional Transport Model for a New BRT Line Passenger Demand Prediction The General Modeling Method,” in Proceedings of International Conference on Technology and Social Science, 2017.

[6] N. D. A. Praditya, "Pemodelan transportasi moda sepeda motor kota Samarinda untuk tahun 2016,” Institut Teknologi Sepuluh Nopember, 2017.

[7] V. A. Upa, "Perhitungan jumlah permintaan potensial Bus Rapid Transit (BRT) Mamminasata koridor 1 dengan menggunakan spacial conventional transport model," Institut Teknologi Sepuluh Nopember, 2017.

[8] J. Gupta and N. H. Shah, "Origin Destination Transportation Models: Methods,” Int Jr. Math. Sci. Appl., vol. 2, no. 2, pp. 819825, 2012.

[9] P. Glenn, I. Thorsen, and J. Ubøe, "A microeconomic approach to distance-deterrence functions in modeling journeys to work," 2001.

[10] A. Rasouli, "Calibrating the Distance-Deterrence Function for the Perth Metropolitan Area,” Curtin University, 2018.

[11] J. S. Shrewsbury, "Calibration of trip distribution by generalised linear models,” University of Canterbury. Department of Civil and Natuaral Resources Engineering, 2012.

[12] N. J. Evans and J. Pooler, "Distance deterrence effect in constrained spatial interaction models of provincial migration," Can. J. Reg. Sci., vol. 3, no. Autumn, pp. 256-279, 1987.

[13] H. Suprayitno, V. Ratnasari, and N. Saraswati, "Behavior of trip length distribution pattern due to the variation of trip length interval determination,” IPTEK J. Eng., vol. 4, no. 1, pp. 7-12, May 2018.

[14] D. F. Pearson, V. G. Stover, and J. D. Benson, “A procedure for estimation of trip length frequency distributions,” Texas, 1974.

[15] H. Suprayitno, N. Saraswati, and C. P. Fajrinia, "Developing a method for measuring the quality of a sample based trip length distribution for urban trip,” Rekayasa Tek. Sipil - REKATS, vol. 3, no. 3, pp. 252-258, 2016.

[16] H. Suprayitno, V. Ratnasari, and N. Saraswati, "Experiment Design for Determining the Minimum Sample Size for Developing Sample Based Trip Length Distribution,” in IOP Conference Series: Materials Science and Engineering, 2017, vol. 267, no. 1, p. 012029. 